\title{
CONSTRUCCIÓN DISCURSIVA DE LA UTOPÍA EN LA CAÍDA DEL ÁGUILA DE CARLOS GAGINI
}

\author{
Minor Herrera Valenciano \\ Universidad de Costa Rica \\ minorj2007@hotmail.com
}

\begin{abstract}
Resumen: En este trabajo se busca sistematizar las funciones que posee la utopía desde el punto de vista del discurso literario y cómo se van plasmando a lo largo del texto La caída del águila de Carlos Gagini. Además, se analiza cómo, a partir de dichas funciones es posible la construcción de espacios utópicos, como la Isla del Coco, en el que se manifiesten los anhelos del autor por unificación de la región centroamericana y su desarrollo tecnológico.
\end{abstract}

Palabras clave: Gagini, Discurso, Utopía, Humanismo, Sociedad, Ciencia.

\begin{abstract}
In this work we seek to systematize the functions that utopia has, from the point of view of literary discourse and how they are reflected throughout the text The fall of the eagle by Carlos Gagini. In addition, it is analyzed how, from these functions, the construction of utopian spaces is possible, such as the Isla del Coco, in which the author's wishes for the unification of the Central American region and its technological development are manifested.
\end{abstract}

Keywords: Gagini, Discourse, Utopia, Humanism, Society, Science. 


\section{Introducción ${ }^{1}$}

Tratar el tema de la construcción discursiva de la utopía es siempre complejo, pues el término utopía podría delimitarse, al menos, de tres formas distintas. En primer lugar, la palabra utopía representa en sí misma un problema de índole etimológico, ya que la construcción que Moro (2011, p. 28) realiza, basándose en la palabra griega тó modificada al agregársele en prefijo "u-". Esto resulta sorprendente e incluso malicioso, ya que dicho prefijo no es posible encontrarlo en la lengua griega, pues en ella lo más cercano a "u" serían los prefijos "ou", que indica la negación o falta de algo (no, sin) y "eu", cuya significación se aproximaría a "lo mejor" (el bien máximo, la felicidad). Así las cosas, ese "u" de la utopía plantea un serio problema, pues encierra en sí mismo dos definiciones contrastantes, al mismo tiempo. Aunque parece un detalle trivial pues, en la mayoría de los trabajos sobre el tema, se acostumbra traducir la palabra utopía como "no lugar" o "lugar imposible o inexistente", no deja de hacer pensar en que si Moro (como humanista que era, conocía bien la cultura clásica y esto incluye, desde luego, el helenismo y la lengua griega) hubiera querido que su "topos" únicamente tuviese un carácter irreal o imposible, sin duda habría optado expresamente por "ou-topía" o, aún mejor, por "a-topía", haciendo uso del prefijo "a", que en griego clásico significa "sin" y que remite a la carencia o imposibilidad de la

\footnotetext{
${ }^{1}$ Este trabajo forma parte del proyecto de investigación "La Construcción discursiva de la utopía en la obra Literaria de Carlos Gagini”, con el código N 836-B6-06,1 del Centro de Investigaciones sobre Diversidad Cultural y Estudios Regionales y la Vicerrectoría de Investigación.
} 
existencia de algo y que, además, desde el punto de vista pragmático, era el más utilizado por los antiguos griegos.

Por otra parte, el término utopía tiene, entre muchas acepciones, la de designar a un modelo literario que se relaciona estrechamente con la ciencia ficción (Moylan, 2000, p. 67) en tanto expresan formas de considerar el mundo muy distintas y distantes de las que podrían considerarse reales, por ejemplo, sociedades extremadamente avanzadas en cuanto a tecnología, ciencia y conocimientos, futuristas, humanistas, entre una variedad infinita de posibilidades. Entonces, la utopía como género literario posee algunas funciones discursivas que conviene retomar y que, sin duda alguna, podrán constatarse en especialmente en La caída del águila de Carlos Gagini.

Ahora bien, la mayor parte de la crítica literaria costarricense, entre ellos Quesada (1988, p.142), concuerda que la obra literaria de Carlos Gagini es la que ejemplifica, con mayor fundamentación, el antiimperialismo surgido en Costa Rica a principios del siglo XX y que esto la convierte en un campo textual fértil, en relación con el deseo de crear escenarios utópicos de unión, orden y progreso; no obstante, la cantidad de investigaciones y documentos críticos que giran en torno a este tema, en general, son escasos, siendo así, que específicamente relacionadas con el texto La caída del águila el número se reduzca todavía más.

Al hacer un breve Estado de la Cuestión, es posible percatarse de tal falencia de información. Por una parte, se encuentra la tesis de licenciatura titulada "La caída del águila y la libre determinación de los pueblos", escrita a cuatro manos, por Marta Soto y Sergio Quirós, en 1978, la que, en resumen, 
señala puntos importantes como la lucha antiimperialista de las naciones centroamericanas y, en general, la oposición determinada ante cualquier atisbo de antiimperialismo. Así como la firme convicción que posee Gagini en relación con que todos los países centroamericanos (y del mundo entero) se $u_{n a n}^{2}$ y posean el derecho de crear su propia suerte y de controlar sus destinos. Este análisis fue desarrollado a partir del método estructuralista, a nivel de modelos actanciales y fundamentado en la teoría de Greimas.

Por otra parte, Acuña (1984, p. 155) desarrolló la tesis de licenciatura titulada "Carlos Gagini: su vida y su obra en el contexto nacional e hispanoamericano", en la que se destaca la importancia de dicho autor en relación con la creación de una conciencia antiimperialista y el ensalzamiento de lo autóctono y nacional. Esta autora plantea que Gagini demostró mediante sus textos la posibilidad de crear una identidad propia $y$, además, cimentó, a partir de su literatura, las bases de una posible conciencia utópica centroamericana (aunque jamás llegó a consolidarse): la unión de todos los pueblos.

Unido a lo anterior, Soto (1986, pp. 17-20) publicó un artículo llamado "Valor literario de Gagini”" en función de su novela La caída del águila, en el que se hace énfasis en la importancia que dicho autor poseen en relación con la construcción de una ideología «antiyanqui» en Costa Rica y el alcance que su obra pudo tener en la construcción de una identidad nacional. Posteriormente, Bolaños (1987) publica "Carlos Gagini y su ideología antiimperialista en La caída del

\footnotetext{
${ }^{2}$ Hay que recordar en su autobiografía titulada Al través de mi vida, Gagini afirma que uno de sus sueños fue siempre el ideal de una Centroamérica unida. Esto hace pensar que, al día de hoy, Gagini seguiría anhelando tal deseo.
} 
águila", cuyo contenido presenta temas similares al de Soto, en el sentido en que, al igual que el anterior, este analiza la obra de Gagini a partir de su alcance ideológico.

Subsiguientemente, Quesada (1988) analizó la obra de Carlos Gagini en uno de los apartados de su libro La voz desgarrada. Él se aproxima a partir de ciertas consideraciones relacionadas con el género de ciencia-ficción, el cual no parece apreciar del todo, ya que menciona, al respecto de La caída del águila, que Gagini se apoya en un «marco ingenuo, esquemático y fantasioso del discurso juliovernesco» (p.149). Ciertamente, esta afirmación refleja que para Quesada dicho texto de Gagini no posee tanto valor literario como otros, en cuanto a caracteres como originalidad y verosimilitud.

Dos años más tarde, se conocerá el artículo "Carlos Gagini: La caída del águila y su concepto de paz mundial", también de Bolaños (1990, pp.15-24), en el que analiza el texto desde la perspectiva de Barthes. En su abordaje examina las secuencias, los rastros y los informantes con el objetivo de probar los posicionamientos ideológicos de los personajes y lo que motiva sus distintos comportamientos.

Ulteriormente, Sanabria (1998, pp. 43-59) en "De la identidad nacional a la global en La caída del águila y Parque Jurásico" muestra, a partir de la comparación del texto y de la película, la asimilación de la imagen nacional al orden global y con esto, los cambios que ha implicado el proceso de globalización en la forma en que se concibe la identidad centroamericana y costarricense.

Finalmente, uno de los artículos que, a juicio personal, analiza con mayor detalle la obra en cuestión es el de Ríos 
(2013, pp. 16-28) titulado "Releyendo La caída del águila de Carlos Gagini: la mediación científica y la nostalgia”, en el que, en resumen, analiza cómo el texto de Gagini evoca la nostalgia de una Costa Rica que perdió su rumbo en relación con la idea de progreso científico, desde antes de la Primera Guerra Mundial y donde la construcción de una utopía se refleja en la necesidad de retomar el camino perdido.

Tal como se observa, ante tal escases de estudios que aborden el texto, resulta imperioso acercarse a él con perspectivas novedosas; es por esta razón que en el presente artículo se partirá de la función de la utopía como modelo de construcción discursiva de manera tal que se muestre cómo Carlos Gagini, valiéndose de una actitud claramente antiimperilista y representada por varios personajes en el texto, construye lo que sería para sí la utopía y el espacio ideal en el cual desarrollarla.

\section{Funciones utópicas discursivas en La caída del águila: teoría y evidencias}

$\mathrm{Al}$ analizar el texto de Gagini, es necesario hacer un repaso por las funciones que posee la utopía, en relación con la manera en que se construyen los textos de este género. Tillich (1986, p.353), por ejemplo, sostiene que la novela utópica se caracteriza por poseer lo que podría denominarse "función anticipadora", es decir, que se anticiparía al futuro próximo (o no tan próximo), al acontecer de hechos que se constatarán con el paso de los años. 
Tal como se puede apreciar en un sinnúmero de intervenciones que Roberto Mora, nieto de Juanito Mora, presenta para contrarrestar los argumentos de Mr. Adams, representante del imperialismo en la región:

Si la dejásemos adueñarse de los mercados de América, nuestras industrias, que alimentan a millones de obreros, perecerían infaliblemente y una espantosa catástrofe sobrevendría en nuestra patria (...) las grandes naciones no se preocupan de la libertad ni de los intereses de las débiles y que todo su afán se cifra en convertirlas en consumidoras de sus productos (Gagini, 1981, p. 111-112)

Es posible notar cómo Roberto Mora da a conocer lo que posiblemente sucedería si la región centroamericana $y$, específicamente, Costa Rica cediera sumisamente ante las pretensiones de alguna nación con deseos de expansión imperialista, hecho que va generando cierta incomodidad en el presente de la narración y que sirve como la chispa de ignición para el deseo de construir un sitio ideal, donde se puede desarrollar una nación y donde todos pueden alcanzar la plenitud.

Por otra parte, Jameson (2006, p.69) piensa que, en la novela, otra de las premisas indispensables para la construcción de un discurso utópico es la función colectiva, es decir, presentar los deseos colectivos, especialmente los que guardan como principal objetivo el integrar una comunidad que acoja $y$ proteja a todos sus miembros por igual.

Dicha función se presenta claramente en el texto con aseveraciones como esta: 
No, señor Ministro: los pueblos como los individuos, no necesitan someterse a la autoridad de un poderoso; pueden asociarse para obras ingentes de interés colectivo y nada tienen que temer de agresores ambiciosos y perversos si en su favor limita el apoyo de otros pueblos amantes de la moral y el orden. El tiempo lo dirá: soy joven y espero ver los frutos de mi obra (Gagini, 1981, p. 89).

Aunque esa es sin duda una posición muy utópica, no debe descuidarse el hecho de que las utopías son, aunque no parezcan, consideraciones particulares sobre el mundo, es decir, los deseos de un individuo que presenta su visión de lo que considera el ideal.

Unido a lo anterior, es claro cómo Gagini pone en voz de su personaje Roberto Mora la idea de que únicamente por medio de la unificación de esfuerzos y el apoyo mutuo entre naciones, será posible alcanzar los anhelos de una nación completamente libre de sistemas opresores. En este sentido, el pasaje anterior demuestra la ideología antiimperialista y la creencia en la posibilidad de desarrollar una nación completamente libre, en donde las decisiones recaigan sobre sus pobladores y no sobre personas externas que no poseen la mínima noción de su realidad.

Ahora bien, hay quienes consideran, como Mumford (2013, p. 67), que una de las funciones más sobresalientes de la utopía, en relación con la construcción de un discurso narrativo, es la de que expresa una forma de escapar de la realidad repugnante ("función escapista"), o sea, enfocada en disminuir el impacto que el mundo real tiene sobre el espíritu y la psique del ser humano. Ese repudio por la realidad presente es puesto en común por Roberto Mora, el protagonista, 
cuando intenta explicar a Fanny, la hija de Mr. Adams, por qué se ha enfrascado en dicho proyecto:

¡Cuánto me repugna el contacto del mundo! Bajezas, intrigas, calumnias, ruines venganzas, chismes innobles, vapor de odio que sofoca y marea, en vez de puras brisas cargadas de amor y simpatía. (Gagini, 1981, p. 166)

Lo más interesante de la función escapista y del pasaje antes mostrado es que, el repudio de la realidad permite justamente que se engendre el sentimiento de cambio y el anhelo de construcción de una realidad mejor, que lógicamente permita vivir en armonía en todos los sentidos, individual, humana, política, científica, entre otras. Esto no se deja de lado en La caída del águila, antes bien, dicho repudio permite que Roberto Mora tenga claro cuál es el objetivo principal de su proyecto:

Yo nací para amar, Fanny; para proporcionar a mis semejantes los medios de ser felices; para tender la mano a los desvalidos y compartir con ellos sus penas (...). Yo quisiera ver la tierra ocupada por centenares de pueblos libres y felices, saneada y cultivada, capaz de contener y alimentar una población que no se multiplicara estúpidamente como ahora; desearía ver a los hombres todos equilibrados, exentos de vicios, disfrutando plácidamente de la vida; sin guerras, ni pestes, ni penas (Gagini, 1981, p. 166).

Nótese como Gagini, mediante los diálogos de Roberto Mora, construye discursivamente lo que para él sería la verdadera utopía, ese deseo de «... renovar allí el idilio del paraíso» (p.166), una renovación que tiene como punto de 
partida la liberación del encadenamiento imperial que Estados Unidos ha impuesto a Costa Rica y toda la región centroamericana.

Hasta ahora se han mostrado tres funciones de la utopía en la literatura; sin embargo, no son las únicas, puesto que es posible encontrarse con dos más con las que la mayoría de estudiosos de la utopía están de acuerdo y que, además, se colocan como conditio sine qua non un texto puede ser considerado utópico: en primer lugar, concuerdan en que la narrativa utópica debe enfocarse en "construir" crítica social y a esta función la denominan "epistemológica". A la cual recurre Gagini en todo momento, pues, como se ha visto en los pasajes anteriormente citados, la realidad de Roberto Mora es repugnante y justamente es así, por los vicios y las conductas desequilibradas de la especie humana, pues «está loca; el hombre no es más que un ser desequilibrado» (p.166), cuyas sociedades, antes de unirse al proyecto utópico de Mora, estaban «sumidas en los vicios, roídas por las enfermedades, sin caminos, ni agricultura ni industrias» (p. 57).

No obstante, la función "epistemológica" va más allá de la simple crítica de la realidad, antes bien de lo que se trata es de una inversión total de esa realidad cuestionable, pues lo que se busca es un cambio, tanto a nivel textual, con la presentación de lo nuevo, como a nivel del lector, en tanto él se apropie del sentimiento de cambio generado desde el texto, es decir, que en lugar de fijarse únicamente en denunciar y satirizar los vicios que aquejan a la sociedad, dicha función, permitirá que la literatura se enfoca en refutar los vicios (cualesquiera que sean) por medio de la negación total de la sociedad en la que se 
despliegan, a través de la imaginación de una sociedad completamente nueva, pero cuya realización resulta en imposible de alcanzar consecuentemente por los vicios que intenta impugnar.

Tales deseos de cambio y propuestas de un mejor lugar para vivir son imaginados por Roberto Mora y sus compañeros y subsecuentemente serían imaginadas por Carlos Gagini, cuando se menciona que:

Roberto contemplaba en su imaginación a las naciones unidas, no por la presión de la fuerza sino por los lazos del amor: los hombres libres y felices; los pueblos sin guerras; las sociedades mejoradas por la educación, exentas de vicios y de crímenes; las ciudades saneadas, embellecidas y risueñas; los hogares, sin lágrimas y rebosantes de bienestar y de paz. (Gagini, 1981, p. 180)

La cita anterior corresponde exactamente con lo que afirma Adorno (1983, p. 50), en relación con la construcción discursiva de la utopía: «negar lo existente para mostrar lo ficticio». Unido a lo anterior, Horkheimer (1998) menciona que la utopía en la literatura tiene, desde la función epistemológica, dos posibilidades; por un lado la crítica de lo que es, es decir, de la realidad (tal como se mencionó anteriormente) y la descripción de lo que debería ser, es decir, una posición política que mencione o elabore las pautas a seguir para llevar a cabo la utopía y, como queda manifiesto, a esto se le denomina función política, ya que, por una parte, critica al político y las formas de gobiernos que no cumplen con las expectativas del pueblo; un ejemplo de ello lo brinda Roberto Mora cuando menciona que 
ni él y ni sus compañeros son «enemigos de los pueblos, sino de los malos políticos que los arruinan» (Gagini, 1981, p. 56),

mientras que, por otro lado, coincide con las demás funciones, ya que su afán es proponer cuál debería ser la mejor realidad posible (el deseo utópico), pero no se queda solo en la propuesta, sino que tal se lleva a cabo con esperanza en una, también posible, realización. Esta función transversa La caída del águila desde la primera página hasta la última. Se deja en claro que solo es posible alcanzar el ideal de una sociedad si quien la gobierna (el político) tiene el interés en ella, si no se dedica a imponer su régimen de forma despiadada, es decir, considerando que «los pueblos tienen derecho-como los individuos- a desenvolver libremente sus energías y a que nadie pueda oprimirlos en nombre del progreso y de la moral política» (Gagini, 1981, p. 61).

En esta construcción de un discurso utópico, es posible encontrar la función pedagógica, la cual tendría por principal objetivo promover, en el lector y en el estudio de las utopías, el deseo de un cambio en la sociedad que habita. Tal concepción es posible notarla en varios de los pasajes más destacados de La caída del águila, por ejemplo: "Propongo un brindis por la futura libertad y fraternidad de todos los pueblos" (Gagini, 1981, p. 83). "Dentro de poco nuestra obra estará consumada, ustedes serán puestos en libertad y el mundo entero conocerá detalladamente la labor que hemos realizado por salvarlo" (Gagini, 1981, p. 85).

Gómez (2007, p. 42.) menciona, al respecto, que esta función se enfoca en hacer pensar a los seres humanos sobre su existencia y participación en la sociedad y acerca de la 
posibilidad de nuevas sociedades potenciales, tal como Roberto Mora lo enfatiza cuando menciona que «los cinco piratas de la isla del Coco van a aniquilar el poderío de todas las grandes potencias y dejar a los pueblos, grandes y pequeños, en absoluta libertad para disponer de sus destinos» (Gagini, 1981, p. 86). Asimismo, cuando se menciona la autoderterminación que alcanzarían los pueblos, una vez derrotado el enemigo: «Rendido el ejército americano y desarmado el mundo entero, los pueblos comenzarían a gozar por primera vez de su libertad y a labrarse por sí mismos su bienestar y su independencia». (Gagini, 1981, p. 156)

A partir de lo anterior, es posible deducir que la utopía, en literatura, posee la advocación de ofrecer planos arquitectónicos con medidas perfectas para la restauración de las ciudades $y$, en casos específicos, como los mostrados anteriormente, fórmulas políticas o sociales con lo que podría buscarse soluciones a los problemas que supone la realidad, pues, tal como se comentó líneas atrás, las utopías finalmente son proyectos individuales. El único problema es que, en la mayoría de las ocasiones, estos proyectos se tornan un tanto exagerados y sumamente difíciles de cumplir, al punto que podrían calificarse como ciencia ficción (Moylan, 2000, p.29), tal como sucede en La caída del águila. No obstante, a pesar de lo anterior, siempre habrá que reconocer que la literatura utópica, más que representar un lugar que no existe (un outopos), quiere mejorar la realidad y presentar un buen lugar (eu-topos) mediante ideas, cuya diversidad podría ser unificada en deseos de equidad, convivencia, avance tecnológico y humanismo: en la construcción de espacios utópicos. 


\section{La Isla del Coco: construcción discursiva de espacio utópico}

La construcción discursiva de la utopía y del espacio utópico en la novela La caída del águila de Carlos Gagini permitió al autor tener mayor libertad narrativa (Quesada, 1988, p. 140), en la medida en que podría presentar el desprecio por la realidad histórica, que coincidían con su pensamiento, es decir, el derrumbamiento del imperialismo provocado por la conjunción de esfuerzos entre alemanes, japoneses y centroamericanos. Esta nueva construcción de la utopía se alejaba de la forma tradicional (expuesta, por ejemplo, en El árbol enfermo), es decir, la que presentaba la oposición contra el imperio en personajes realistas caracterizados y que le permitirían «al narrador plantear los conflictos políticos de manera más abstracta, al utilizar un criterio más elástico de verosimilitud»(Quesada, 1988, p.142). De este modo, Gagini tendría mucha más libertad para tratar su realidad histórica, de manera que su crítica antiimperialista no fuese una crítica hacia dentro, es decir, criticar el imperialismo en Costa Rica o desde Costa Rica, sino que ahora podría realizar su crítica hacia el exterior, esto es, como lo indica Quesada enfrentando la voz de la oligarquía, del nacionalismo, y el humanismo latinoamericano contra la «vOz imperialista» del utilitarismo estadounidense.

En ese sentido, el discurso utópico le permitirá a Carlos Gagini construir una realidad verosímil impregnada, desde luego, de su ideología antiimperialista, que poseerá matices 
científicos, tan exagerados en algunos momentos que rayaría, como se mencionó en apartados anteriores, en la ciencia ficción.

En esa construcción discursiva del espacio utópico, la Isla del Coco es mostrada como la base en la que Los caballeros de la libertad ${ }^{3}$ iniciarán su contra guerrera ante el imperialismo yankee; no obstante, el plan inicia con el protagonista en Japón; Mora (no se tiene claro el motivo por el que se encontraba allá) se percata de que Estados Unidos se ha apoderado de buena parte del territorio centroamericano. Esto lo hace pensar en la posibilidad de formar un grupo armado, que le haga la contra a los imperialistas y, por tal razón, decide buscar ayuda en otras personas que tuvieran una posición parecida a la suya, en relación con el expansionismo yankee.

Unido a lo anterior, el proyecto de Roberto Mora es claro: borrar de la faz de la tierra centroamericana todo lo relacionado con Estados Unidos, por el bien de su gente y del mundo entero. Es así que encuentra a Amaru, un japonés a quien su gobierno lo veía con cierto recelo por sus ideas anarquistas, además, de algunos centroamericanos (de El Salvador y de Honduras) y un alemán.

A partir de este momento empieza a construirse un discurso con una clara intención política, complementada con ideales cientificistas (recordar la función política expuesta en el apartado anterior), es decir, una utopía política, que pronto tomará matices de utopía científica, como se mostrará más adelante.

\footnotetext{
3 Desde el inicio se presenta una utopía humanista manifiesta en el sentido de que Mora, el personaje principal, logra reunir aliados, también centroamericanos para perseguir un ideal: derrocar el imperialismo de los Estados Unidos.
} 
La utopía política se empieza a gestar desde el deseo de liberación y es claro con afirmaciones como esta:

Estando en Japón supe la ocupación de las Repúblicas Centroamericanas por tropas de los Estados Unidos y desde entonces me juré consagrar toda mi vida y energías a romper las cadenas de mi patria o por lo menos a vengarla (Gagini, 1981, p. 84)

Ese ideal antiimperialista, no podría lograrse solo, es por eso que inicia el proceso de reclutamiento de opositores del régimen estadounidense y de esta manera encuentra otros centroamericanos que compartían sus ideales. Estos personajes son «Manuel Delgado, recién salido de la Escuela Politécnica y Francisco Valle, distinguido médico y naturista, ambos millonarios... y ardiendo en deseos de sacudirse de la dominación extranjera ${ }^{4} \gg$ (Gagini, 1981, p. 84).

En este reclutamiento, Mora regresa a Japón, un país que describe «tan perjudicado casi como nosotros por el imperialismo yanqui» (Gagini, 1981, p.85). Estando ahí construye tres submarinos (pues considera la imposibilidad de vencer al enemigo sin que se cuente con un armamento de última generación) con los que llegará a explorar la Isla del Coco.

Desde es posible notar algunos ideales humanistas manifiestos principalmente en la noción de unidad, en el

\footnotetext{
4 La cita anterior ofrece un dato interesante: no solo deben tener el mismo pensamiento antiimperialista, sino que, además, debe tener una misma posición social, es decir, deben ser acaudalados, ya que, al parecer no basta con el deseo de luchar contra los yankees, es necesario poseer recursos económicos para armarse contra ellos.
} 
sentido de que Roberto Mora, el personaje principal, logra reunir aliados, también centroamericanos para perseguir un ideal: derrocar el imperialismo de los Estados Unidos. Una vez que se ha conseguido la meta, lo siguiente será iniciar el desarme y la desarticulación del equipo lo cual representa, como lo sostiene Quesada (1988), la victoria de «los ideales humanísticos latinoamericanos por la conformación general de sus miembros sobre los militares y mercaderes imperialistas anglosajones» (p.43).

Unido a lo anterior, para alcanzar los anhelos antiimperialistas, deberán desarrollar un espacio desde el cual actuar y es así como, al igual que una Atlántida ${ }^{5}$, la Isla del Coco se convierte en el espacio ideal para iniciar una utopía, vista esta como el lugar desde el que se iniciará la ruptura de las ataduras que ha impuesto el imperio. Es el sitio ideal, pues incluso Roberto Mora reconoce que «difícil es imaginar paraje más adecuado para refugio» (Gagini, 1981, p.19). Esa idea se refuerza con el recuerdo de que la isla fue, en algún momento, escondite de piratas.

La estrategia que se utilizará para la construcción de esta base utópicamente tecnologizada será la mímesis con el ambiente. En ese sentido, la red de cavernas que Mora explora, perfectamente podría ocultar el arsenal que posee y, además,

\footnotetext{
${ }^{5}$ Los diálogos Timeo y Critias fueron escritos por Platón en el ocaso de su vida y de su actividad literaria, lo cual se presume, pudo ser aproximadamente entre los años 369 al 348 a.C. En dichos textos, a la Atlántida se la concibe como un espacio utópico, es decir, una ciudad levantada con una arquitectura y un sistema político "perfecto" (hecho que se verá reforzado por su descripción de la república ideal, propuesto en la República), cuya estructura social (equidad) debería ser el modelo de las urbes sucesoras, aunque no así la codicia de poder de sus gobernantes, hecho que devendrá en el desmoronamiento de la ciudad. Además, su existencia es datada nueve mil años antes del reinado de Solón de Atenas.
} 
«podrían albergar cómodamente más de un centenar de personas» (Gagini, 1981, p.30).

Así las cosas, esa isla agreste, inhóspita de «selvas impenetrares que la cubren» (Gagini, 1981, p.5), cuya imagen trae a la mente la imagen de lo «salvaje, hirsuto y amenazante ... lleno de miasmas mortíferos de ciénagas, miradas de venenosos reptiles en acecho debajo de la maleza, millares de bestias feroces» (Gagini, 1981, p.4), irá cambiando conforme interviene Mora y su equipo, quienes, gracias a la estrategia militar y a su consideración de la tecnología como medio para romper el yugo imperialista, domesticarán esa naturaleza agreste y se servirán de ella hasta crear un paraje idílico, una utopía humanista, pero al mismo tiempo científica.

En este sentido, Gagini estaría creando en la Isla del Coco aquello que él consideró lo ideal, pero que, al mismo tiempo, faltaba a nuestra nación y que, dicho sea de paso, había criticado en su ensayo "La ciencia y la metafísica":

La decantada inferioridad de los latino-americanos con respecto a los sajones proviene exclusivamente de la educación inadecuada. En efecto, en estos países nuevos y tan escasamente poblados no se dirige la atención de la juventud hacia el aprovechamiento de las riquezas naturales... (1918, p. 57)

Las palabras de la cita anterior serán cambiadas por Gagini, en voz de Roberto Mora, de manera que, en La caída del Aguila, sí se apreciará el progreso y se consolidará la utopía:

¡Error! No pasarán cuatro días sin que usted, señor Secretario, se convenza de que el ingenio latino no es 
inferior al sajón y que este ignorado ciudadano de la más pequeña y desgraciada república latinoamericana tiene motivos suficientes para enorgullecerse pensando que él sólo, sin más auxiliares que su escasa ciencia y sin más arma que la justicia, va a destruir el imperio más poderoso de los tiempos modernos. (Gagini, 1981, p.105).

Los ideales de progreso y de desarrollo tecnológico se encarnan en Roberto Mora, quien, como lo afirma Ríos (2013), «rompe con la tautología entre la raza y la ciencia-tecnología generada desde los centros que afecta a las colonias europeas» (p.8).

Es así como la isla, poco a poco irá tomando forma y se irá metamorfoseando, de un espacio agreste hacia un espacio donde los anhelos de progreso, no solo centroamericanos sino latinoamericanos, se materializarán y donde una raza oprimida y menospreciada finalmente se manifestará como emancipada y valerosa.

En el avance, en la transformación del ambiente selvático, logran construir una base completamente electrificada que, además, cuenta con una pequeña línea férrea, indetectable desde la vista aérea y fácil de ocultar con una ligera cubierta de pasto. Pero ese lugar, conforme se va transformando, va generando afectos y sensaciones, pues, por ejemplo, mientras para los yankees como Mr. Adams y Fanny, es un espacio indómito, terrible e inaceptable para vivir, para Roberto Mora ahora representa la tierra más cercana a su verdadero hogar.

Esto quiere decir que la tarea de domesticar la isla se debe a la necesidad de convertirla en un hogar, en un territorio en el que se pueda vivir con las comodidades propias de su 
condición de humano (además, millonario) y donde los ideales de su grupo (recordar la función colectiva) se vean reflejados en su forma de ordenar y gobernar dicho paraje.

El espacio lujoso en el que convirtió la isla agreste gracias a la intervención de la tecnología se observa muy bien cuando Roberto «guio a sus invitados a una especie de gruta, amueblada con lujo oriental y alumbrada por fanales de luz incandescente... Fanny se creía transportada a uno de los lujosos hoteles de Nueva York» (Gagini, 1981, p.83).

Se podría considerar dicha cita, también, como una descripción de lo que Mora (y por extensión Gagini) deseaba alcanzar para la confederación centroamericana y por extensión para Costa Rica. Más aún si se considera, como apunta Ríos (2013, p.15), que esa utopía científica no se presenta por mera casualidad; menos aún, si se toma en cuenta la historia del desarrollo científico presente en la Costa Rica de Gagini, pues el desarrollo científico descollante mostrado sí fue posible alguna vez; no obstante, para la época en la que Gagini escribió el texto, únicamente quedaban vestigios de este, de modo que, con nostalgia, el texto lo revisita, puesto que nunca pudo consolidarse y, por eso mismo, se constituye en utopía. Es lo que Ovares (1993) menciona como el «lamento por la patria idílica perdida y su resucitación mediante la escritura.» (p.147).

No obstante, en medio de tanto desarrollo tecnológico y de recurrencias nostálgicas al pasado que nunca llegaron a desarrollarse (como lo llama Boym, 2001), se muestra, además, otro tipo de nostalgia, aquella de orden bucólico que incita siempre a llevar una vida reposada en el campo y la cercanía 
con la naturaleza, quien al mismo tiempo será proveedora de todo aquello que se necesite:

Ninguna vida podría ser más agradable que la de esta isla, en donde además de absoluta libertad gozamos de todas las comodidades deseables. Tenemos habitaciones casi lujosas, víveres en abundancia, nuestros pescadores nos traen diariamente ostras y gran variedad de pescados, nuestra vacada nos suministra leche, quesos y mantequilla, y la huerta toda clase de verdura y delicadas frutas. Distraemos nuestros ratos de ocio con lectura de obras de una selecta biblioteca o tañendo instrumentos de música que nos proporcionan deliciosas veladas (Gagini, 1981, p. 73-74)

Como se aprecia, la utopía que se desarrolla en la isla está equilibrada, tal como se nota, entre el prominente desarrollo surgido a partir de la tecnología (que se concentra en los vericuetos de la isla), las comodidades aristocráticas y los caracteres que apuntan a la vida campesina, al idealismo bucólico romántico que apunta hacia una vida gozada en la tranquilidad del campo.

Sin embargo, a pesar de ese acercamiento al bucolismo, el deseo de convertir la isla en una base militar de primer nivel y a Costa Rica en una potencia militar que avergonzaría a las grandes ciudades del imperio es mayor. Eso sí, debe conformarse en una potencia apegada a ciertos principios, pues, a pesar de que Mora tiene suficiente armamento para destrozar a los Estados Unidos y posicionarse con una nueva fuerza imperialista, sus principios y valores le impiden hacerlo. Claramente puede notarse cómo, a partir de lo que él mismo llama la «condición de latinoamericano», establece una ética 
militar que desarrollará en la Isla del Coco y que extenderá a lo largo y ancho de latinoamérica: «los latinos no tenemos ese instinto de crueldad que caracteriza a otras razas.»(Gagini, 1981, p. 98).

Con dicha cita es posible fortalecer la idea plantada en el imaginario costarricense desde que se inició el proceso de construcción de la identidad nacional, es decir, la condición pacífica del individuo. No obstante, Sanabria (1998), menciona que el sentimiento de represión ocasionado por la invasión extrajera a la arcadia centroamericana, solo puede desembocar en una recuperación del espacio idílico, mediante una solución bélica, profundamente contrastante- según el ideal pacifistacon el «sentir de los habitantes» (p. 47). Sin embargo, tal beligerancia es constantemente disminuida por las aseveraciones de Mora, quien, a pesar de conocer el poder destructivo de su armamento (por ejemplo, cuando tiene la oportunidad de destruir varios aviones enemigos), menciona que tienen el «poder de hacer, pero no el deseo» (Gagini, 1981, p. 118), afirmación que refuerza nuevamente el ideal pacifista de dicho personaje, para quien las muertes, cuanto menos haya, mejor, independientemente de quien sea.

Otro punto relacionado con dicho ideal pacifista, es que no hay ni un solo militar costarricense en toda la novela, pues se menciona que son japoneses los que custodian la base y quienes han construido y manipulan el armamento (Gagini, 1981, p.78). Unido a esto, es notorio cómo Mora decididamente se aparta del conflicto bélico, cediendo a otro su participación, por ejemplo, al mexicano Morelos, quien tendría por misión destrozar el contingente naval británico que 
se encontraba en Jamaica; sin embargo, cuando se trataba de participar discursivamente en relación con ética era él (Mora) quien tomaba la batuta (Gagini, 1981, pp. 131-132).

En ese sentido, se presenta en el texto la necesidad por tecnificarlo todo y mostrar, en un personaje como Mora, la confluencia de lo bélico y lo pacífico, al mismo tiempo recursos importantes para concretar los ideales latinos, en una época en la que la literatura fungía como mecanismo para la construcción de la identidad.

Es así como la isla se convierte en el espacio donde la utopía se hace posible, donde las ideas de unidad y grandeza del humanismo se conjuntan con las del poderío y superioridad basado en la ciencia, para dar paso a un nuevo concepto de nación pacífica y avanzada, a la altura de las grandes potencias. Se trata, entonces, de otorgarle una voz propia a la emergente nación y simbólicamente posicionarla en un nivel similar al de muchas otras.

\section{Consideraciones finales}

En La caída del águila, a pesar del recurrente uso de expresiones relacionadas con la ciencia y de descripciones tecnificadas de todos los espacios posibles, no se llega a robustecer una estrategia efectiva que tomara con sensatez la necesidad de una verdadera inversión en el desarrollo científico costarricense, es decir, no va más allá de la espacio de la ciencia ficción descrita en el texto, no trasciende en el sentido de que no hay avances tecnológicos reales o que se estuviesen 
impulsando en la Costa Rica (o en Centroamérica) en la época en la que Gagini escribió el texto.

Es así como, al no haber un impulso real, el texto se presenta como una utopía, por un lado, humanista, pues desde las funciones utópicas a las que se recurren para la construcción del discurso, se proponía la unión del pueblo centroamericano con la intención de expulsar al imperio opresor, mientras que, por otro, muestra un escenario utópico científico, pues un costarricense, gracias a los conocimiento científicos que poseía, a su preparación académica y la ayuda que recibe de otras naciones (Japón y Alemania), bastante tecnificadas para la época, consigue someter al imperio estadounidense.

Finalmente, al habérsele atribuido tanto valor al discurso técnico-científico y a la noción de orden y progreso asociadas a él, esta novela, construye un espacio donde se fundamenta la utopía, pero, al mismo tiempo, esa utopía tiene su origen en la nostalgia de un pasado que prometía un desarrollo tecnológico rápido y de avanzada, pero que por alguna razón se detuvo y no fue más que una ilusión. Así es que, como lo apunta Ríos (2013, p. 24) en La caída del águila, el discurso utópico se construye sobre la añoranza ocasionada por un deseo de desarrollo que no logró consolidarse. 


\section{Referencias bibliográficas}

Acuña, M; M. (1984). "Carlos Gagini: su vida y su obra en el contexto hispanoamericano". Tesis de Licenciatura en Literatura. San José: Universidad de Costa Rica.

Adorno, T. (1983). Teoría estética. Barcelona: Orbis.

Bolaños, S. (1987). "Carlos Gagini y su ideología antiimperialista en La caída del águila”. Revista Filología y Lingüística, vol.13 (2), 51-60

(1990). "Carlos Gagini: La caída del águila y su concepto de paz mundial”. Revista Filología y Lingüística, vol.16 (1), 15-24

Frutiger, Perceval. Los mitos de Platón. New York: New York University press, 1976

Gagini, C. (1918). La ciencia y la metafísica. San José: Falcó y Borrasé

\section{Editorial Costa Rica}

(1981, $10^{\mathrm{a}}$ ed.) La caída del águila. San José:

García, E. (1998). Utopía en Moro, Thomas. Madrid: Akal

Gómez, C. (2007). "La utopía entre la ética y la política: reconsideración". Revista Internacional de Filosofía Política, vol 29 (2), 39-64

Horkheimer, M. (1998) La utopía en Historia, metafísica y escepticismo. Barcelona: Altaya

Jameson, F. (2006) “Arqueologías del futuro”. El viejo topo. Jul. 68-73

Jouvenel, B. (1982). Utopías y pensamiento utópico. Madrid: Espasa-Calpe 
Moylan, T. (2000). Scraps of the untainted sky: Sciencie fiction, utopia and Dystopia. Westview press.

Moro, T. (2011). La Utopía. Madrid: Akal.

Mumford, L. (2013). Historia de las utopías. Logroño: Pepitas de calabaza.

Ovares, M. et al. (1993). La casa paterna. Costa Rica: Editorial Universidad de Costa Rica

Platón (1992). Diálogos I, II, III, IV. Trad. Mariángeles Durán y Francisco Lisi. Madrid: Gredos

Quesada, A. (1988). La voz desgarrada: La crisis del discurso oligárquico y la narrativa costarricense, 1917-1919. San José: Editorial de la Universidad de Costa Rica.

Ríos Q; V. (2013). "Releyendo La caída del águila de Carlos Gagini: la mediación científica y nostalgia de una novela antiimperialista de ciencia-ficción". Revista letras. University of Texas and Austin.

Sanabria Sing, C. (1998). "De la identidad nacional a la global en La caída del águila y Parque Jurásico”. Revista de Filología y Lingüística de la Universidad de Costa Rica, vol 24 (2), 4359

Soto, M. (1986). "Valor literario de Gagini en función de su novela La caída del águila”. Revista Káñina, vol 10 (2): 17-20

Soto Marta y Quirós S (1978). "La caída del águila y la libre determinación de los pueblos". Tesis para optar el título de Licenciados en Filología Española. Escuela de Filología Lingüística y Literatura: Universidad de Costa Rica. 
Tillich, P. (1982). Crítica y justificación de la utopía en Manuel, Frank. Utopías y pensamiento utópico. Madrid: EspasaCalpe.

Fecha de recepción: 05/02/2018

Fecha de aprobación: 18/03/2019 